Recebido: 09/10/2015

Aprovado: 20/11/2016

\title{
Resenha do livro
}

\section{SILVA, Vandeilton Francisco da. A festa de N. S. do Carmo em Boa Vista /Roraima: conflitos e disputas de poder - 1892-1927. Campina Grande, EDUFCG, 2012.}

Paulo Sérgio Rodrigues Silva

A obra resenhada é o resultado de uma tese de mestrado em História Social realizado por Vandeilton Francisco da SILVA, que é licenciado em História pela Universidade Federal da Paraíba (atual Universidade Federal de Campina Grande), especialista em Relações Fronteiriças pela Universidade Federal de Roraima, é também mestre em História Social pela Fundação Severino no Estado do Rio de Janeiro. Atualmente é professor concursado da Secretaria Estadual de Educação no Estado de Roraima, onde atua na Educação Básica com o componente curricular História no Ensino Médio. Como jovem pesquisador é dedicado aos estudos de questões regionais de Roraima especificamente temáticas relacionadas às relações de poder e ao catolicismo. Silva não faz parte de uma tradição de historiadores, mas se lança se como possibilidade e insere no movimento de produção e pesquisa histórica na área da história cultural. Suas publicações, ainda que incipientes, perfazem um roteiro promissor para a contribuição de uma história regional crítica.

O leitor poderá perceber que Silva, comedido nas palavras de cunho ideológico, é bastante cuidadoso para não direcionar seus escritos a uma concepção redundante dos fatos históricos. De modo bastante acadêmico deixa as fontes "falarem" por si só, no entanto, não deixa de tecer uma interpretação contextualizada e analítica, acrescentado sua criticidade em

\footnotetext{
* Mestrado na Universidade Federal de Roraima. E-mail para contato: psergio04@gmail.com
} 
relação aos fatos narrados. É bastante equilibrado em termos de construção de sentidos na história.

O ponto de partida de Silva é a abordagem política da festa religiosa de Nossa Senhora do Carmo, em Boa Vista, Rio Branco, hoje Estado de Roraima, entre os anos de 1892 a 1927, frente aos vários interesses sociais, econômicos, políticos e também religiosos das classes dominantes da época pesquisada. Os objetivos do autor com relação ao seu objeto de pesquisa é compreender os porquês da festa tenha tornado alvo de conflitos e disputas entre os fazendeiros e os religiosos; analisar as relações políticas existentes e o jogo de interesses e também entender as motivações da introdução do culto a santa na região.

Para explicitar o objeto de pesquisa, Silva levanta uma hipótese que a festa em homenagem a Nossa Senhora do Carmo representava para os fazendeiros locais (Boa Vista$\mathrm{RR}$ - séc.XIX e início do século XX), um instrumento de exibição e poder. Os meios políticos, econômicos, coerção física, cargos públicos por si só não legitimava o poder e a prepotência dos fazendeiros era necessária o elemento religioso, através da festa como status. Já para os monges Beneditinos a festa era uma forma de assegurar "a retomada das atividades eclesiásticas a viabilizariam desenvolver no Rio Branco, parte da reestruturação econômica pretendida pela Ordem no Brasil” (SILVA, 2012, p. 20).

Contexto histórico ao qual Silva concentra sua pesquisa é região do Rio Branco, onde o poder político foi marcada pelas organizações num sistema de hierarquia, subserviência, dependência, lealdade e proteção, além de muitos outros elementos se constituíram como parte de determinados pactos estabelecidos entre fazendeiros e seus aparentados e amigos, que ficou conhecido como coronelismo, que durante a primeira República “(...) o governo Central em troca do apoio das lideranças regionais, geralmente estruturadas nas organizações políticas lideradas por um grande proprietário (latifundiário, fazendeiro etc.), oferecia favores políticos, recurso públicos, além de outros interesses como poderes regionais, todos advindos do poder central". (SILVA, 2012, p. 99).

Os fundamentos teóricos que orientam as suas afirmações sobre relações de poder fundamenta-se em Michel Foucault, afirmando que "Este defende que o exercício do poder não se legitima apenas pela repressão, pois do contrário dificilmente conseguiria alcançar ou obter o que há de produtor no poder, bem como dificilmente seria obedecido pela sociedade em que ele é exercido" (SILVA, 2012, p. 46). Acrescenta que poder pode ser definido como definido como algo múltiplo que se mantém. Assim, portanto, o poder “é reconhecido e aceito justamente por não se usufruído apenas como força negativa e repressiva, mas por 
permear, produzir coisas, induzir ao prazer, formar saber e produzir discurso". (IDEM, IBIDEM).

Quanto a opção metodologia utilizado na pesquisa de Silva está diretamente vinculada ao aprofundamento da hipótese levantada sendo uma mescla de: documental, exploratória, bibliográficas e metodologia da história oral "Durante o ano de 2005, tive o privilégio de entrevistar um grupo de pessoas moradoras da parte velha da cidade de Boa Vista, hoje histórica" (SILVA, 2012, p. 21). Diz Melo que: "A opção teórica e a adoção de dados pressupostos argumentativos têm uma relevância fundamental na escolha do método". Silva com muita habilidade consegue correlacionar opção teórica e hipótese com metodologia e método da pesquisa.

Apresentadas as questões iniciais quanto aos aspectos metodológicos, a hipótese, contexto do autor, opção teórica vamos ao que é essencial o resultado da pesquisa de Silva, isto é, as ideias centrais da obra, a tese defendida pelo autor. Primeiramente, apenas para situar o leitor, o livro está dividido em três capítulos.

No primeiro capítulo, que foi divido em seis tópicos, é apresentado o contexto histórico dos cultos devocionais, da origem da festa de Nossa Senhora do Carmo.. Silva descreve a presença dos missionários (monges) carmelitas na região da bacia do rio Branco responsáveis pela entronização do culto mariano a Nossa Senhora do Monte Carmelo, de origem do Oriente Médio, como também o contexto político. O autor aborda o culto a partir das relações políticas e religiosas acontecidas nos aldeamentos envolvendo os padres Carmelitas e os grupos de poder instalados na região. Silva faz uma longa discussão, talvez desnecessária, sobre a Ordem Carmelita e sua presença na Amazônia, descrevendo em detalhes as cronologias dos fatos envolvendo os missionários aos acontecimentos ligados ao dito "processo evangelizador", que culminou com a expulsão dos mesmos. Também, nesse capítulo, recebe destaque especial à origem da formação dos grandes latifúndios roraimenses, com a introdução do gado, irá marcar a origem dos conflitos e as relações de poder e interesses na região. Silva finaliza o primeiro capítulo a criação da Paróquia de Nossa Senha do Carmo e o início das mudanças festivas, preparando o leitor para o segundo capítulo, já que deixa bem claro "quem é manda na região".

O segundo capítulo talvez o mais importante, a meu ver, condensa o desdobramento da hipótese levantada por Silva de que a festa realizada em homenagem a Nossa Senhora do Carmo, no Rio Branco, foi objeto de manipulação utilizado como instrumento para beneficiar

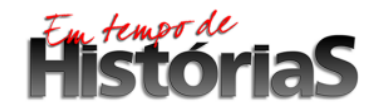


os grandes projetos políticos, econômicos e também religiosos, que envolveram fazendeiros de um lado e missionários do outro.

Afirma Silva que “(...) a organização do evento festivo foi aos poucos passando ao domínio de alguns fazendeiros locais, que a moldaram para fins de interesse políticos e econômicos, contribuindo para transformar a festa em um instrumento de legitimação da hegemonia política local" (2012, p. 76). Ao longo do capítulo é apresentado o principal foco de interesse dos grupos políticos pela festa da santa “(...), pois através dela os fazendeiros ligados ao partido Republicano Amazonense e à Loja Maçônica do Rio Branco procuravam condicionar a realização da festa à presença e importância dos mesmos na região" (p. 72). Silva considera nesse capítulo que o controle das festividades mariana pelos fazendeiros foi determinante para imposição de poderio na região pela classe política, que a partir de um pretexto, a organização da festa, colocava em prática a realização de projetos maiores como a expansão dos latifúndios, o avanço da pecuária e controle políticos na região, como forma de legitimação dos interesses em apenas os grupos de poder. Enfatiza Silva que:

“(...) os fazendeiros do Rio Branco estavam mais interessados em consolidar uma estrutura dominadora, bem como chamar para si a atenção das autoridades políticas estaduais como forma de garantir legitimidade política e conseguirem privilégios locais, bem como pressionar as lideranças do Partido Republicano Amazônico na distribuição de cargos, verbas e na regulamentação de terras públicas adquiridas de forma irregular" (2012, p. $83)$.

Assim o que é central no capítulo segundo compreender as formas de concentração de poder político no Rio Branco. O poder de mando constituído a partir de grupos reinantes buscava aumentar suas influências se utilizando dos eventos religiosos, ao que nos parece, na leitura de Silva, havia pouca determinação religiosa para a constituição de uma devoção festiva autônomo independe das lideranças políticas. O culto a santa passou a ser manipulável conforme os projetos disposto no tabuleiro do jogo de interesses.

O último capítulo o autor destaca a presença da Ordem de São Bento na região da bacia do rio Branco com pretensão não apenas religiosa, mas também empreendedora com projetos voltados ao desenvolvimento local. Os conflitos voltam à cena, pois os projetos dos religiosos e da elite política formada por fazendeiros são divergentes e distintos em suas naturezas. $\mathrm{O}$ coronelismo predominante na região confronta diretamente com os religiosos beneditinos. Impondo à força através de agressões físicas e ameaças os fazendeiros (coronéis)

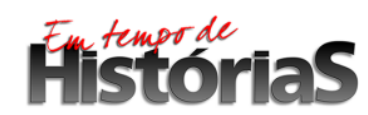


impõem medo a todos aqueles que não se integravam aos seus projetos. Conta Silva que certa vez por ocasião da recusa dos monges em celebrar o batizado de uma criança filho de um fazendeiro, membro da loja maçônica, levou o Coronel Bento Brasil durante a missa ameaçar de morte os religiosos além de proferir palavras furiosas no sentido de afirmar quem realmente detinha o poder de mando na Vila, acrescenta Silva:

"Poder este que credenciava a seu possuidor fazer aberrações contra
qualquer pessoa e, caso os monges não entendessem, se recusando a
contrariar os interesses dos fazendeiros locais, sentiriam as consequências,
pois era inconcebível a qualquer um, que recém-chegado à região, se achasse
no direito de recusar a atender a um pedido de alguém ligado ao grupo
maçônico". (2012, p. 129).

A Igreja também teve o seu poder de mando na região buscou alianças com a elite do Rio Branco com objetivos de assegurar os seus interesses de seus bens materiais na região. Diz Silva que a Igreja não possuía um empenho profundo na evangelização ou na dimensão espiritual. As fontes utilizadas por Silva nos levam a crer que a Igreja, marcada pela presença beneditina, mais do que "salvar almas" tinha como missão ampliar o poder terreno pela conquista material.

\section{Conclusão}

O ponto de partido da obra resenhada foi satisfazer uma curiosidade do autor em relação aos conflitos e disputa de poder no final do século XIX e início do XX. Como resultado de uma tese de mestrado a obra percorreu uma trilha científica com situação-problema, hipótese, tese, metodologias, fontes de pesquisa e conclusões chegadas pelo autor. A obra é coerente internamente todos os argumentos estão relacionados a hipótese e a tese, os capítulos e subtítulos então correlacionados em si. É uma obra relevante, muito embora outros autores já tenham abordado a temática da presença beneditina no Rio Branco, contudo Silva consegue desenvolver uma peculiaridade, que ainda não havia sido explorada, discutir relações de poder e disputas em torno da festa de Nossa Senhora do Carmo. Talvez, uma das fraquezas da obra, foi deixar à margem discussões presença dos indígenas, tão significativa na região estudada pelo autor.

\section{Referências bibliográficas}

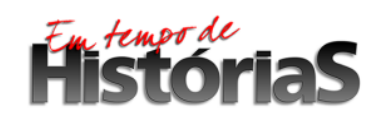


MELLO, Ricardo Marques de. Como escrever uma resenha historiográfica: considerações teóricometodológicas. Revista Em Tempo em Histórias, No. 19 (2011) Brasília. Disponível em: http://seer.bce.unb.br/index.php/emtempos/article/view/6753. Acessado em: 11 out. 2012

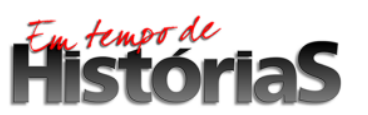

